\title{
Gastrointestinal motility and Intestinal structure following oral exposure to acrylamide in Wistar rats
}

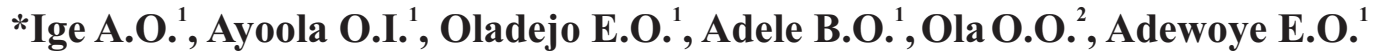

\begin{abstract}
Introduction: Acrylamide, a byproduct of the cooking process, has been reported to be a toxicant with likely carcinogenic properties. Its impairment of gastric function has been previously reported. In this study its effects on gastrointestinal motility and intestinal structure was investigated in male Wistar rats.
\end{abstract}

Methods: Forty-five rats $(120-180 \mathrm{~g})$ were divided into 3 equal groups $(\mathrm{n}=15)$ and treated $p . o$ with either $0.2 \mathrm{ml}$ distilled-water, or acrylamide $(7.5 \mathrm{mg} / \mathrm{kg}$ and $15 \mathrm{mg} / \mathrm{kg}$ respectively) for 28 days. Thereafter, gastric emptying and intestinal motility was assessed. Intestinal structure (duodenum, jejunum and ileum), mucosal and intestinal cell counts were evaluated using histological techniques.

Results: Gastric emptying and intestinal transit time increased $(p<0.05)$ in the experimental (acrylamidetreated; $7.5 \mathrm{mg} / \mathrm{kg}$ and $15 \mathrm{mg} / \mathrm{kg}$ ) groups compared to control. Mucosal cell counts (duodenum, jejunum and ileum) and ileum intestinal cell counts $(\mathrm{p}<0.05)$ were reduced in the experimental groups compared to control. Compared to control, duodenal samples of the experimental groups showed severe coagulative necrosis and sloughing off of the villi, luminal filling with necrotic debris, disruption and necrosis of the crypts of Lieberkühn, moderate polymorphonuclear cell infiltration and vascular congestion. These pathologies albeit with less severity were also observed in the jejunum and ileum of acrylamide treated groups.

Conclusion: Increased oral exposure to acrylamide impairs gastric emptying, intestinal motility, mucus secretion and compromises digestive and absorptive functions of the small intestines, especially the duodenum. These observations may be ascribed to acrylamide-induced impaired neuronal signaling, autonomic neuropathy, oxidative stress, inflammation and cell necrosis.

Keywords: Acrylamide, gastrointestinal tract, gastric emptying, intestinal motility, small intestines

\author{
*Corresponding author \\ Ige A.O. \\ ORCID-NO: http://orcid.org/0000-0003-2981-1256 \\ Email: aby_ige@yahoo.com; ao.ige@mail1.ui.edu.ng
}

${ }^{1}$ Applied and Environmental Physiology Unit, Department of Physiology, University of Ibadan

${ }^{2}$ Department of Veterinary Pathology, Faculty of Veterinary Medicine, University of Ibadan 


\title{
Motilité gastro-intestinale et structure intestinale après une exposition orale à l'acrylamide chez le rat Wistar
}

\author{
*Ige A.O. ${ }^{\text {, }}$ Ayoola O.I. ${ }^{1}$, Oladejo E.O. ${ }^{1}$, Adele B.O. ${ }^{1}$, Ola O.O. ${ }^{2}$, Adewoye E.O. ${ }^{1}$
}

\begin{abstract}
Résumé
Introduction : L'acrylamide, un sous-produit du processus de cuisson, a été signalé comme étant un toxique aux propriétés cancérigènes probables. Son altération de la fonction gastrique a déjà été rapportée. Dans cette étude, ses effets sur la motilité gastro-intestinale et la structure intestinale ont été étudiés chez des rats Wistar mâles.
\end{abstract}

Méthode de l'étude : Quarante-cinq rats (120-180 g) ont été divisés en 3 groupes égaux $(\mathrm{n}=15)$ et traités p.o avec $0,2 \mathrm{ml}$ d'eau distillée ou d'acrylamide $(7,5 \mathrm{mg} / \mathrm{kg}$ et $15 \mathrm{mg} / \mathrm{kg}$ respectivement) pendant 28 jours. Par la suite, la vidange gastrique et la motilité intestinale ont été évaluées. La structure intestinale (duodénum, jéjunum et iléon), les numérations des cellules muqueuses et intestinales ont été évaluées à l'aide de techniques histologiques.

Résultat de l'étude : La vidange gastrique et le temps de transit intestinal ont augmenté $(p<0,05)$ dans les groupes expérimentaux (traités à l'acrylamide; $7,5 \mathrm{mg} / \mathrm{kg}$ et $15 \mathrm{mg} / \mathrm{kg}$ ) par rapport au groupe témoin. Le nombre de cellules muqueuses (duodénum, jéjunum et iléon) et le nombre de cellules intestinales de l'iléon $(\mathrm{p}<0,05)$ ont été réduits dans les groupes expérimentaux par rapport au groupe témoin. Par rapport au contrôle, les échantillons duodénaux des groupes expérimentaux ont montré une nécrose coagulante sévère et une desquamation des villosités, un remplissage luminal avec des débris nécrotiques, une rupture et une nécrose des cryptes de Lieberkühn, une infiltration modérée de cellules polymorphonucléaires et une congestion vasculaire.

Conclusion: Ces pathologies bien qu'avec moins de gravité ont également été observées dans le jéjunum et l'iléon des groupes traités à l'acrylamide. Ces observations peuvent être attribuées à une altération de la signalisation neuronale induite par l'acrylamide, une neuropathie autonome, un stress oxydatif, une inflammation et une nécrose cellulaire.

Mots-clés : Acrylamide, tractus gastro-intestinal, vidange gastrique, motilité intestinale, intestin grêle

\author{
*Corresponding author \\ Ige A.O. \\ ORCID-NO: http://orcid.org/0000-0003-2981-1256 \\ Email: aby_ige@yahoo.com; ao.ige@mail1.ui.edu.ng
}

${ }^{1}$ Applied and Environmental Physiology Unit, Department of Physiology, University of Ibadan

${ }^{2}$ Department of Veterinary Pathology, Faculty of Veterinary Medicine, University of Ibadan 


\section{INTRODUCTION:}

The gastrointestinal tract, also known as the digestive tract or alimentary canal, is often described as the pathway for the entry of food into and the exit of solid waste from the body. Six processes have been highlighted to constitute the digestive process and these include ingestion, propulsion, mechanical or physical digestion, chemical digestion, absorption, and defecation (1). The structural integrity of the gut represents a first line defense mechanism against invasion of foreign pathogens that might have been ingested with food $(2,3)$. It is one of the core diseasefighting systems of the human body as it produces acid and enzymes in the stomach which sterilizes ingested food and thus protects the body from illness and infection (4). The gut barrier is hence essential in the prevention of debilitating disease condition.

Gut motility, the movement of ingested food substances through the gut for absorbing nutrients, water, and electrolytes and eliminating waste products, also represents an essential component required for gut homeostasis and functionality (1). Movement within the gut is accomplished by coordinated contractions and relaxations of the smooth muscles, which is controlled by intrinsic gut neurons, extrinsic signals from the central nervous system and some hormones (5). Three basic gastrointestinal motility patterns have been described and these are segmentation contractions that mix the contents, peristalsis that moves the contents a short distance, and the migrating motor complex (MMC) that propels the contents forward during the fasting state $(5,6)$. For proper digestion of food and excretion of solid waste, the gut integrity and motility therefore needs to be maintained and kept constant.

The small intestines (duodenum, jejunum and ileum) carry out digestive processes leading to the absorption of nutrients such as glucose, amino acids, free fatty acid, glycerol, electrolytes, vitamins and minerals across the villi (or lacteals in the case of fatty acid and glycerol) into the blood stream (1).

Acrylamide, has been described in our previous study (3), is an industrial chemical used in the manufacture of personal care and grooming products, soil conditioners, wastewater treatment, as well as in paper and textile industries $(7,8)$. It is also a by-product of the cooking process having been reported to be a byproduct of heat-processed foods high in carbohydrates e.g. snack foods, potato crisps, breads, cereal products, and coffee (9). Dietary formation of acrylamide is linked to the Millard reaction, which is responsible for browning of food during baking, frying, and roasting (9). Therefore, it is likely that the general populace may be exposed to acrylamide through their diets. Acrylamide consumed with food has been reported to cause various homeostatic disorders in the body, ranging from teratogenic, genotoxic, neurotoxic effects, to disorders of reproductive functions (10).

Though the gastrointestinal (GI) tract represents one of the primary routes of acrylamide absorption (11), its exact effects on the gut remain unclear and require more investigation. In our previous study, we have demonstrated that increased oral acrylamide exposure, compromises the integrity of the gastric mucosal barrier by increasing the activity of gastro-aggressive factors and suppressing gastro-protective factors (3). In this study, the effects of acrylamide exposure on gastric emptying, intestinal motility and intestinal structure (duodenum, jejunum and ileum) were investigated

\section{MATERIALS AND METHODS \\ Animals, Groupings and Treatment Protocol}

Forty-five (45) male Wistar rats (150-

$170 \mathrm{~g}$ ) were maintained at room temperature with alternating day and night cycles, and housed in standard well-aerated laboratory cages. Animals were fed standard rat chow and allowed free access to drinking water ad libitum. Thereafter, animals were randomly divided into 3 groups ( $\mathrm{n}=$ 15). Group 1 was the control group, and animals were given distilled water $(0.2 \mathrm{~mL} /$ animal/day $)$ while animals in groups II and III received $7.5 \mathrm{mg} / \mathrm{kg}$ and $15 \mathrm{mg} / \mathrm{kg}$ body weight of acrylamide (Sigma Aldrich, China) $(12,13)$ respectively. All treatments were given orally for 28days. Animals received humane care, and procedures were in accordance with the Guide for the Care and Use of Laboratory Animals (14), published by National Academy Press, 2101 Constitution Ave. NW, Washington, DC 20055, USA).

\section{Determination of Gastric emptying}

Gastric emptying was evaluated using the hydrated meal method as described by Droppleman et al., (15) and modified by Yeung et al., (16). Briefly, a hydrated meal was prepared from the standard rat chow by placing $45 \mathrm{~g}$ of pellets in $100 \mathrm{ml}$ water. Two (2) milliliters of this hydrated test meal, was administered to overnight fasted animals using oral cannula. Two (2) hours 
after administration of the test meal, the rats were euthanized by an overdose intraperitoneal injection of sodium thiopental $(150 \mathrm{mg} / \mathrm{kg})$. Thereafter, a midline incision was made on each animal to expose the stomach which was then ligated at the cardiac and pyloric regions respectively to prevent spillage of gastric contents. The whole stomach was excised and weighed. Afterwards, an incision was made at the greater curvature and the gastric contents were washed off with distilled water. Excess moisture was blotted from the stomach and thereafter, the empty stomach was weighed. Gastric emptying was determined as follows

Gastric Emptying $(\%)=$

Weight of full stomach-empty stomach X 100 Body weight

\section{Determination of Intestinal motility}

After an overnight fast, gastrointestinal transit time was evaluated using the charcoal meal method. Briefly, the charcoal meal marker was freshly prepared by dispersing $10 \%(\mathrm{w} / \mathrm{v})$ activated charcoal in $5 \%(\mathrm{w} / \mathrm{v})$ gum acacia mucilage in distilled water and then well triturated. Each rat received 4\% charcoal meal $(10 \mathrm{ml} / \mathrm{kg}$ p.o. $) 24$ hours after their respective treatments. After 20 mins of charcoal meal, animals were sacrificed by cervical dislocation. The abdomen was cut open and the whole small intestine to the ileocecal valve was excised. The leading marker was then identified, tied immediately with a cotton thread, and the whole intestine was immersed in 5\% formalin in order to halt peristalsis. The distance travelled by charcoal meal marker and the total length of the intestines was measured in $\mathrm{cm}(\mathrm{s})$. The gastrointestinal transit time was expressed as percentage $(\%)$ of the distance travelled by the charcoal meal to the length of the intestine $(17,18)$.

Intestinal Transit (\%)

$=$ Distance travelled by charcoal meal $\mathrm{x} 100$

Total length of intestine

Determination of Intestinal structure, intestinal cell and mucous cell counts

After an overnight fast, animals were euthanized with an intraperitoneal overdose administration of sodium thiopental. The small intestine was excised, $6 \mathrm{~cm}$ section each from the duodenum (immediately below the pyloroduodenal junction), jejunum (middle of the small intestine) and ileum (immediately above the ilea- caecal junction) (19) were divided in two (3 cm each), washed in running water, fixed in $10 \%$ formalin and processed routinely for paraffin embedding. Each $3 \mathrm{~cm}$ section of the duodenum, jejunum or ileum was processed for either intestinal structural changes using Hematoxylin and Eosin stain (H\&E) or mucous cell and intestinal cell counts using Periodic Acid Schiff (PAS) stains respectively.

\section{Statistical Analysis}

Results expressed as mean $\pm \mathrm{SEM}$ were analysed using one-way analysis of variance (ANOVA) followed by Newman-Keuls' Post hoc test. Comparisons between control and experimental groups were assessed and statistical differences were established at $\mathrm{p}<0.05$.

\section{RESULTS}

Effects of acrylamide exposure of gastric and intestinal motility

Gastric emptying in groups II (acrylamide $7.5 \mathrm{mg} / \mathrm{kg}$ treated) and III (acrylamide $15 \mathrm{mg} / \mathrm{kg}$ treated) was significantly increased $(p<0.05)$ compared to values obtained in group I, the control group $(1.46 \pm 0.17,1.14 \pm$ 0.08 vs. $0.97 \pm 0.05 \%$ ) (Figure 1). Intestinal transit time in groups II $(44.28 \pm 3.32 \%)$ and III $(52.93 \pm 3.44 \%)$ was also significantly increased compared to values obtained in group I (23.98 \pm $3.76 \%$ ) (Figure 2).

\section{Effects of acrylamide exposure on intestinal cell and mucous cell counts}

Intestinal cell counts of the duodenum and jejunum in groups II and III were not significantly different from counts obtained in group I. However, ileum intestinal cell counts in group II and group III were 50.5\% and 35.3\% reduced $(\mathrm{p}<0.05)$ compared to group I (Table 1$)$. Mucous cell counts in the duodenum, jejunum and ileum in groups II and III were significantly reduced $(p<0.05)$ respectively, compared to values obtained group I (Table 2).

\section{Histopathology of the intestines}

Three sections of the small intestines (obtained differently from duodenum, jejunum and ileum) were evaluated for gross structural changes (x100 and x400) using Haematoxylin and Eosin (H \& E) stains. The duodenal samples in group I (control) showed normal duodenal architecture, with normal slender villi (black arrows) and crypts (red arrows). There was also no visible lesion seen (Fig 3; Ia and Ib). Duodenal sections in group II (acrylamide $7.5 \mathrm{mg} / \mathrm{kg}$ 
treated) showed severe coagulative necrosis and sloughing off of the villi (black arrow), necrotic debris filling of the entire intestinal lumen (blue arrow) and severe disruption and necrosis of the crypts of Lieberkühn (red arrow) Fig 3; IIa). At higher microscopic magnification, moderate polymorphonuclear cell infiltration $(\star)$ ) and vascular congestion (\#) were also observed in this group (Fig 3; IIb). In Group 3 (acrylamide $15 \mathrm{mg} / \mathrm{kg}$ treated), duodenal sections showed stunted villi, with mild necrosis at their tips (black arrow). The crypts were mildly affected (red arrow) (Fig 3; IIIa). However, sections also showed moderate polymorphonuclear cellular infiltration ( $\star$ ) and vascular congestion (\#) (Fig 3 ; IIIb)

Sections of the jejunum in group 1 showed normal architecture with sharp villi, goblet cells and normal crypts (Fig 4; Ia and Ib). Jejunum sections in group II showed severe stunting, coagulative necrosis and sloughing off of the apical half of the villi. Cryptal cells were also moderately affected (red arrow) (Fig 4; IIa.) At higher magnification, the presence of moderate vascular congestion was also observed (Fig 4; IIb). Jejunum samples in group III (acrylamide $15 \mathrm{mg} / \mathrm{kg}$ treated), severely stunted villi and coagulative necrosis of the apical half of the villi was observed. The Crypts seen appeared normal (red arrows) (Fig 4; IIIa). However, moderate vascular congestion (\#) was observed (Fig 4; IIIb)

Sections from the Ileum in group 1 show normal architecture with slender villi and crypts that were normal (Fig 5; Ia and Ib). Ileum samples in group II and III showed severe stunting (atrophy) and coagulative necrosis with sloughing off of the apical half of the villi (black arrow), and epithelial debris in the lumen (Crypts however are unaffected (Fig 5; IIa and IIIa). Mild vascular congestions were also observed in ileum samples from both groups II and III respectively (Fig 5; IIb and IIIb).

\section{DISCUSSION}

Acrylamide, an industrial organic compound and monomer of polyacrylamide, is used in the manufacture of many products often used daily (7). The discovery in 2002 that it may be produced when carbohydrate rich food is roasted, fried or baked (20) has sparked several studies into its biological effects. These investigations have reported the neurotoxicity, reproductive toxicity, immune toxicity of acrylamide consumption (21). In a previous study from our laboratory, its ability to impair and compromise gastric integrity has also been reported (3). In this study using similar doses, experimental animals exhibited delayed gastric emptying when exposed to acrylamide at low $(7.5 \mathrm{mg} / \mathrm{kg})$ and high $(15 \mathrm{mg} / \mathrm{kg})$ doses (Figure 1). This suggests the presence of gastroparesis, a condition that affects the gastric muscles and prevents proper gastric emptying (22), in the acrylamide exposed groups. The pathogenesis of gastropariesis appears to be unclear, however it is believed to be due to either autonomic neuropathy of the vagus nerve (23), loss of expression of neuronal nitric oxide synthase (24), loss of the interstitial cells of Cajal (25), impaired muscle function (26) or a combination of these pathologies (27).

This study also shows an increase in gastrointestinal transit time in the oral acrylamide exposed groups (Figure 2) suggesting impaired intestinal motility and a delay in the time for movement of substances through the small intestine. Motility within the gut is said to be due to the coordinated contractions of the tunica muscularis, the smooth muscular layer of the gut (28), that are in close proximity with two groups of spontaneous potential generating interstitial cells, the interstitial cell of Cajal (ICC) and platelet-derived growth factor receptor alpha $\left(\mathrm{PDGFR}^{+}\right)$cell $(28)$. These interstitial cells receive impulses from neuron within the gut intrinsic enteric nervous system (ENS), specifically the myenteric plexus, innervate gut muscle cells, resulting in coordinated contraction and motility, which is also influenced by extrinsic signals from the central nervous system (CNS), blood-circulating hormones as well as paracrine and immune factors $(5,28)$. Acrylamide consumption has been reported to disrupt fast axonal transport resulting in central-peripheral neuropathy (29). Its ability to disrupt nitric oxide signaling at nerve terminals has also been reported $(31,32)$. Acrylamide, an electrophile, preferentially forms adducts with nucleophilic sites on macromolecules resulting in reduced neurotransmission at central and peripheral synapses via disruption of signaling pathways (32). It is therefore not unlikely that the reduced gastric emptying and impaired intestinal motility observed in the experimental groups may be due to gastric autonomic neuropathy and reduced signal transmission between the ENS, the interstitial cells (ICC and PDGFR $\alpha^{+}$) and the smooth muscle cells of the gut wall.

The small intestine, functionally divided into the duodenum, jejunum and ileum, is the site of nutrient digestion and absorption in the gut. 
Generally, the mucosa and submucosa of the small intestines form large numbers of folds arranged in a circular fashion in the lumen and contain microvilli which increases the surface area for nutrient and electrolyte absorption (33). The epithelium of the small intestine lines the luminal surface and it contains numerous components that aid the digestion and absorption process. Some of these include enterocytes which are tall columnar cells that have an absorptive function, Goblet cells that secrete mucin and crypts of Lieberkühn. These crypts contain stem cells that replace cells lost due to abrasion, and enteroendocrine cells that synthesize and secrete hormones (34). This study shows severely compromised duodenal villi structure and luminal lining, inflammation and necrotic crypts of Lieberkühn in both acrylamide treated groups (Figure 3Ia-IIIa; Ib-IIIb) suggesting an impairment in the ability of the duodenum to release digestive enzymes and thus impede the digestive process. Furthermore, this may account for the impaired rate of gastric emptying observed in both groups, as secretions from the crypts of Lieberkühn have been reported to control the rate of gastric emptying from the stomach via hormonal pathways (35). The reduction in duodenal mucosal cell counts in the experimental groups (Table 2) further suggests a reduction in mucus production and hence an increase in the susceptibility of the intestinal lining to erosion. However, intestinal cell counts of the duodenum and jejunum in the experimental groups were unchanged suggesting the preservation of gut immune function despite the presence of acrylamide-induced intestinal pathologies.

The jejunum and ileum of the acrylamide treated groups also showed similar pathologies (Figure 4Ia-IIIa;Ib-IIIb and 5Ia-IIIa;Ib-IIIb) as observed in their corresponding duodenal samples albeit with reduced severity also suggesting a compromised digestive and absorptive process as well as increased susceptibility to intestinal lining erosion. However, cell lining replacement, hormonal secretion and gut immune function in these groups may still be functional as the crypts of Lieberkühn observed in the experimental groups appeared normal. However, ileum intestinal cell counts were markedly reduced (Table 1) suggestion a likely comprise of gut immune function. Observations from the intestinal samples in this study appear consistent with an increase in oxidative stress, inflammation and apoptosis which is in accordance with the findings of El-Mehi and El-Sherif (36) who also reported mucosal erosions, and depletion of the surface mucus of the stomach following oral exposure to acrylamide. Findings from this study also appear to be in accordance with our previous study, which reported compromised gastric mucosal integrity via increased activity of gastroaggressive factors and suppression of gastroprotective factors following oral exposure to acrylamide (3).

In conclusion, data from this study shows that increased exposure to oral acrylamide impairs gastric emptying, intestinal motility, mucus secretion via reductions in mucosal cell counts, and may compromise the ability of the small intestines, especially the duodenum, in carrying out its digestive and absorptive functions. These observations may be ascribed to the reported ability of acrylamide to induce impaired neuronal signaling, autonomic neuropathy, oxidative stress, inflammation and necrosis.

Acknowledgments: The authors wish acknowledge Dr. Adeola T. Salami of the Laboratory for Gastrointestinal Secretion and Inflammation Research, Department of Physiology, College of Medicine, University of Ibadan for assistance offered in the course of the study.

Conflict of interest: The authors declare no conflict of interest exists for this study.

\section{REFERENCES}

1. Hall, JE. Gastrointestinal Physiology, In: Guyton and Hall Textbook of Medical Physiology (12th edition.) 2011. Philadelphia, PA: Elsevier, 753803.

2. Hammer AM, Morris NL, Earley ZM, Choudhry MA. The First Line of Defense: The Effects of Alcohol on Post-Burn Intestinal Barrier, Immune Cells, and Microbiome. Alcohol Res. 2015; 37(2):209-222.

3. Ige AO, Onwuka OM, Emediong IE, Odetola AO, Adele BO, Adewoye EO. Oral administration of acrylamide compromises gastric mucosal integrity in Wistar rats. J. Afr. Ass. Physiol. Sci. 2019; 7(1): 7-16.

4. Smith JL. The role of gastric acid in preventing foodborne disease and how bacteria overcome acid conditions. J Food Prot. 2003; 66(7):1292303. doi: 10.4315/0362-028x-66.7.1292.

5. Kitazawa T, Kaiya H. Regulation of Gastrointestinal Motility by Motilin and Ghrelin in Vertebrates. Front Endocrinol, 2019;10: 278. Doi: $10.3389 /$ fendo. 2019.00278 
6. Takahashi T. Interdigestive migrating motor complex - its mechanism and clinical importance. J Smooth Muscle Res. 2013;49:99-111. doi:10.1540/jsmr.49.99

7. Friedman M. Chemistry, biochemistry, and safety of acrylamide. A review. J Agric Food Chem. $200330 ; 51(16): 4504-26$. doi : $10.1021 / \mathrm{jf030204+}$

8. Exon JH. A review of the toxicology of acrylamide. J Toxicol Environ Health B Crit Rev. $2006 ; 9(5): 397-412$. d o i : 10.1080/10937400600681430.

9. Mottram DS, Wedzicha BL, Dodson AT. Acrylamide is formed in the Maillard reaction. Nature. 2002; 419(6906):448-9. doi: 10.1038/419448a.

10. Palus K, Bulc M and Całka J Effect of Acrylamide Supplementation on the Population of Vasoactive Intestinal Peptide (VIP)-Like Immunoreactive Neurons in the Porcine Small Intestine. Int. J. M o 1. S c i . 2020; 21: 9691 ; doi:10.3390/ijms21249691

11. Zödl B, Schmid D, Wassler G, Gundacker C, Leibetseder V, Thalhammer T, Ekmekcioglu C. Intestinal transport and metabolism of acrylamide. Toxicology 2007; 232: 99-108.

12. Zenick H, Hope E and Smith MK. Reproductive toxicity associated with acrylamide treatment in male and female rats. J. Toxicol. Environ. Health, 1986; 17: 457.

13. Eman MA, Amany YMR. Some Studies On Acrylamide Intoxication In Male Albino Rats. Egypt. J. Comp. Path. \& Clinic. Path. 2008; 21(4): $222-245$

14. National Research Council (US) Institute for Laboratory Animal Research. Guide for the Care and Use of Laboratory Animals. published by National Academy Press, 2101 Constitution Ave. NW, Washington, DC 20055, USA, 1996.

15. Droppleman DA, Gregory RL, Alphin RS. A simplified method for assessing drug effects on gastric emptying in rats. J Pharmacol Methods. 1980; 4(3):227-30. doi: 10.1016/01605402(80)90014-5.

16. Yeung C-K, McCurrie JR and Wood D. A simple method to investigate the inhibitory effects of drugs on gastric emptying in the mouse in vivo. $\mathrm{J}$ Pharmacol Toxicol Methods 2001; 45: 235-240.

17. Sandhiya S, Dkhar SA, Krishna PRM, Ramaswamy S. Role of ion channel modifiers in reversal of morphine-induced gastrointestinal inertia by prokinetic agents in mice. Indian J Exp Biol. 2008; 46: 60 - 65.

18. Tembhurne SV, Sakarkar DM. Effect of Murraya Koenigii leaves Extracts on Gastrointestinal motility: Involving Calcium Channel Innervation in Mice. Arch Pharm Sci \& Res 2009; 1(2): 189 . 193.

19. Vigueras R.M, Rojas-Castaneda J, Hernandez R, Reyes G. and Alvarez C. Histological characteristics of the intestinal mucosa of the rat during the first year of life. Laboratory Animals
Ltd. Lab Anim. 1999; 33, 393-400.

20. Tareke E, Rydberg P, Karlsson S, Eriksson M, Törnqvist M. Analysis of acrylamide, a carcinogen formed in heated foodstuffs. J Agric Food Chem 2002;50:4998-5006.

21. Zamani E, Shokrzadeh M, Fallah M, Shaki F. A review of acrylamide toxicity and its mechanism. Pharm Biomed Res 2017; 3(1): 1-7. doi:10.18869/acadpub.pbr.3.1.1

22. Rodríguez-Varón A, Zuleta J. From the physiology of gastric emptying to the understanding of gastroparesis. Rev Colomb. Gastroenterol. 2010;25(2), 219-225.

23. Guy RJ, Dawson JL, Garrett JR, Laws JW, Thomas PK, Sharma AK, Watkins PJ. Diabetic gastroparesis from autonomic neuropathy: surgical considerations and changes in vagus nerve morphology. J Neurol Neurosurg Psychiatry. 1984; 47(7):686-91. doi: 10.1136/jnnp.47.7.686.

24. Oh JH, Pasricha PJ. Recent advances in the pathophysiology and treatment of gastroparesis. J Neurogastroenterol Motil. 2013; 19(1):18-24. doi:10.5056/jnm.2013.19.1.18

25. Bashashati M, McCallum RW. Is Interstitial Cells of Cajal-opathy Present in Gastroparesis-. J Neurogastroenterol Motil. 2015; 21(4):486-493. doi:10.5056/jnm 15075

26. Bhetwal BP, An C, Baker SA, Lyon KL, Perrino BA. Impaired contractile responses and altered expression and phosphorylation of $\mathrm{Ca}^{2+}$ sensitization proteins in gastric antrum smooth muscles from ob/ob mice. J Muscle Res Cell Motil. 2013; 34(2):137-49. doi: 10.1007/s10974013-9341-1.

27. Sullivan A, Temperley L, Ruban A. Pathophysiology, Aetiology and Treatment of Gastroparesis. Dig. Dis Sci. 2020; 65(6):1-17. doi: 10.1007/s10620-020-06287-2

28. Sanders KM, Koh SD, Ro S, Ward SM. Regulation of gastrointestinal motility--insights from smooth muscle biology. Nat Rev Gastroenterol Hepatol. 2012; 9(11):633-645. doi:10.1038/nrgastro.2012.168

29. Sickles DW, Stone D, Friedman MA.. Fast axonal transport: a site of acrylamide neurotoxicityNeurotoxicology, 2002; 23:223-251.

30. LoPachin RM, Barber DS. Synaptic cysteine sulfhydryl groups as targets of electrophilic neurotoxicants. Toxicol Sci. 2006; 94:240-255.

31. LoPachin RM, Barber DS, Gavin T. Molecular mechanisms of the conjugated alpha, betaunsaturated carbonyl derivatives: relevance to neurotoxicity and neurodegenerative diseases. Toxicol Sci. 2008; 104(2):235-49. doi: 10.1093/toxsci/kfm301.

32. LoPachin RM, Gavin T. Molecular Mechanism of Acrylamide Neurotoxicity: Lessons Learned from Organic Chemistry Environ Health Perspect $2012 ; 120: 1650-1657$. http://dx.doi.org/10.1289/ehp.1205432.

33. Rao JN, Wang JY. Regulation of Gastrointestinal 
Mucosal Growth. San Rafael (CA): Morgan \& Claypool Life Sciences; 2010. Intestinal Architecture and Development. Available from: https://www.ncbi.nlm.nih.gov/books/NBK5409 $8 /$

34. Umar S. Intestinal stem cells. Curr Gastroenterol Rep. 2010;12(5):340-348. doi:10.1007/s11894010-0130-3.

35. Ahmed M, Ahmed S. Functional, Diagnostic and Therapeutic Aspects of Gastrointestinal
Hormones. Gastroenterology Res. 2019;12(5):233-244. doi:10.14740/gr1219.

36. El-Mehi AE and El-Sherif NM (2015). Influence of acrylamide on the gastric mucosa of adult albino rats and the possible protective role of rosemary. Tissue Cell. 47(3): 273-83. doi: 10.1016/j.tice.2015.03.005. 


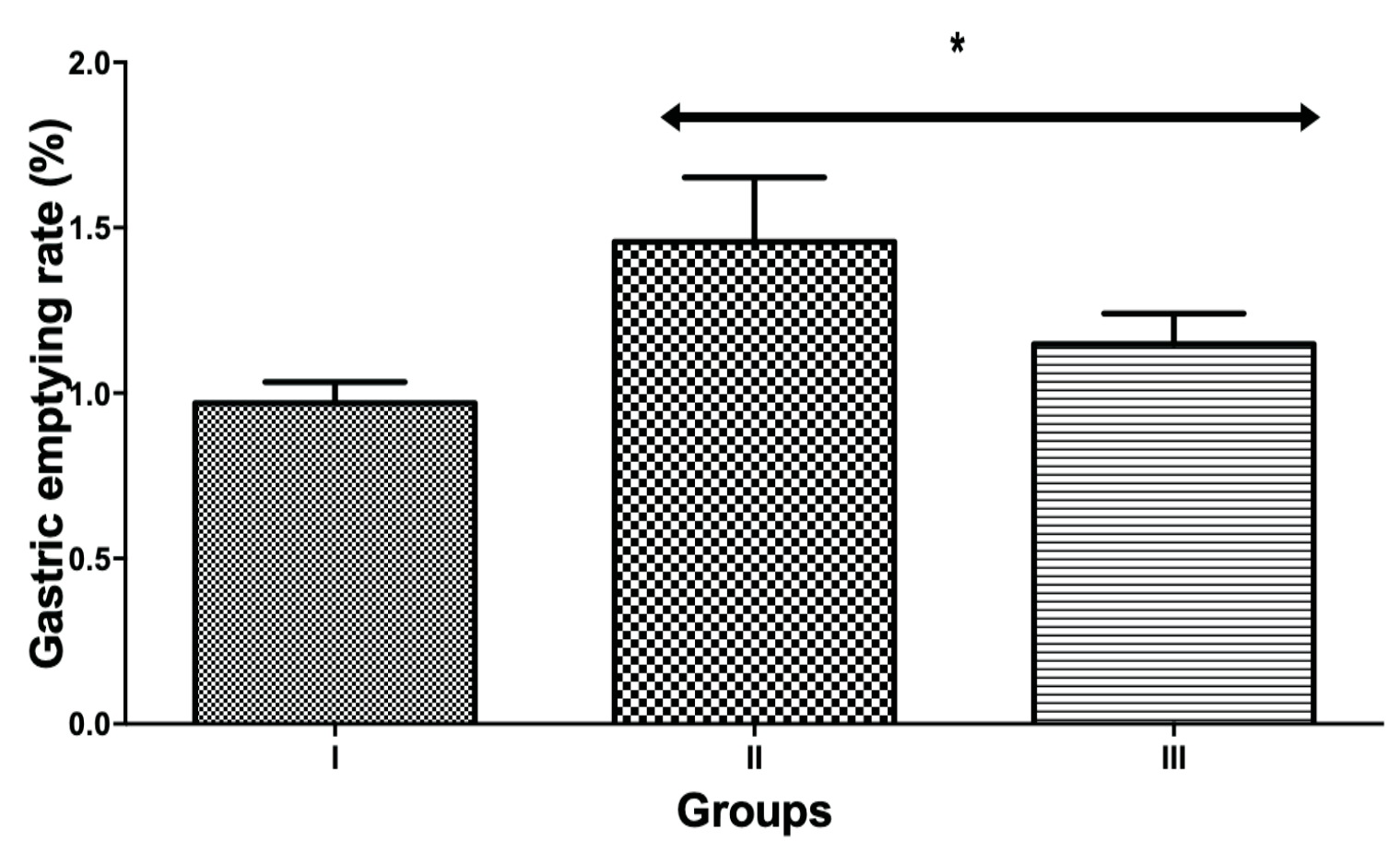

Figure 1. Gastric empty rate in control and experimental groups.

Values are mean \pm SEM $(n=5)$ and * indicates values that are significantly different from group I. $\mathrm{I}=$ Control group; II = Acrylamide $(7.5 \mathrm{mg} / \mathrm{kg})$ treatment group; III = Acrylamide $(15 \mathrm{mg} / \mathrm{kg})$ treatment group.
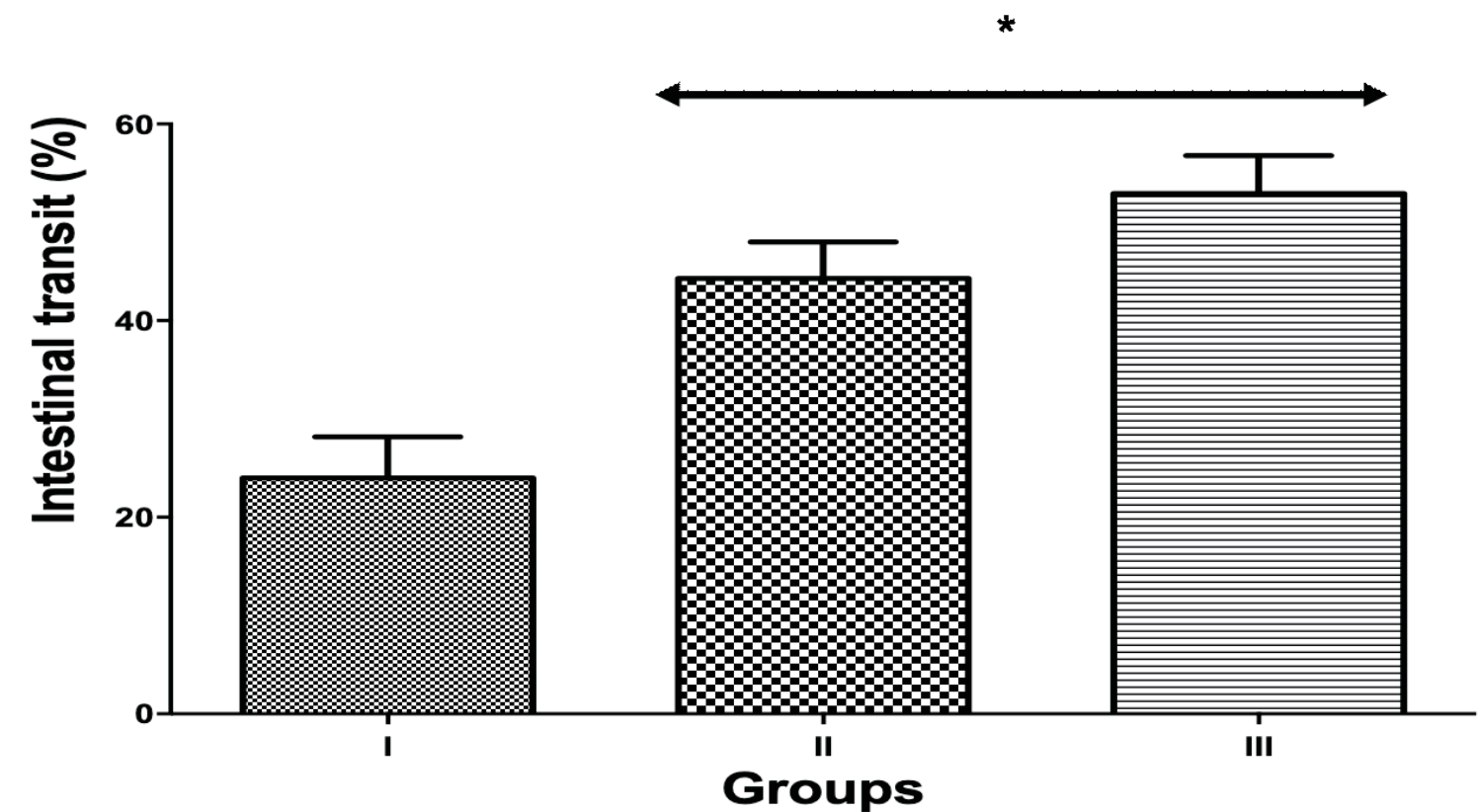

Figure 22. Gastrointestinal transititime incontrpland experimental grpunss. Values are mean \pm Vathes (

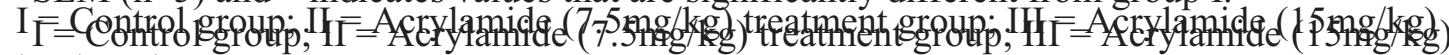
treatmentrogroutp. 
Table 1: Intestinal cell counts in control and experimental groups

\begin{tabular}{llll}
\hline & \multicolumn{3}{c}{ Groups } \\
\cline { 2 - 4 } & $\mathbf{1}$ & II & III \\
Duodenum & $754.7 \pm 20.6$ & $630.3 \pm 114.7$ & $746.5 \pm 55.5$ \\
Jejunum & $932.8 \pm 106.3$ & $763.7 \pm 122.6$ & $972 \pm 9.4$ \\
Ileum & $1292 \pm 118.5$ & $639 \pm 36.5^{*}$ & $836 \pm 114.1^{*}$ \\
\hline
\end{tabular}

Values are Mean \pm SEM $(\mathrm{n}=5)$.

* indicates values that are significantly different from group I (control) values.

$\mathrm{I}=$ Control group; $\mathrm{II}=$ Acrylamide $(7.5 \mathrm{mg} / \mathrm{kg})$ treatment group;

III = Acrylamide $(15 \mathrm{mg} / \mathrm{kg})$ treatment group .

Table 2: Mucous cell counts in control and experimental groups

\begin{tabular}{llll}
\hline & \multicolumn{3}{c}{ Groups } \\
\cline { 2 - 4 } & I & II & III \\
\hline Duodenum & $327.8 \pm 16.2$ & $210.1 \pm 28.4^{*}$ & $240.5 \pm 4.3^{*}$ \\
Jejunum & $411.7 \pm 89.8$ & $260.6 \pm 7.3^{*}$ & $300 \pm 37.3^{*}$ \\
Ileum & $372.6 \pm 35.1$ & $297.5 \pm 19.6^{*}$ & $238.2 \pm 22.6^{*}$ \\
\hline
\end{tabular}

Values are Mean \pm SEM $(n=5)$.

* indicates values that are significantly different from group I (control) values.

$\mathrm{I}=$ Control group; $\mathrm{II}=$ Acrylamide $(7.5 \mathrm{mg} / \mathrm{kg})$ treatment group;

$\mathrm{III}=$ Acrylamide $(15 \mathrm{mg} / \mathrm{kg})$ treatment group. 

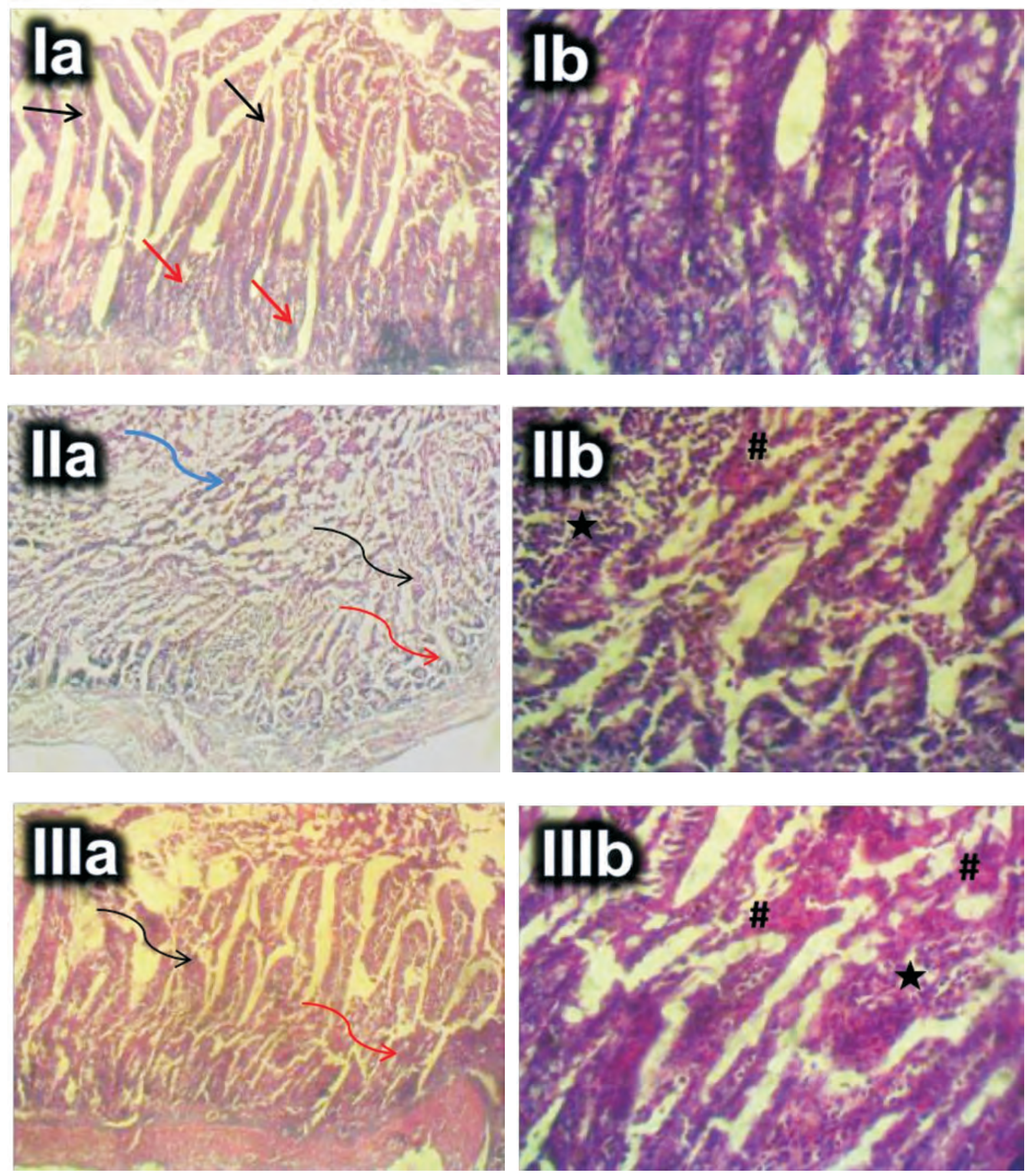

Figure 3 (Ia -IIIa x100; Ib -IIIb x400) Duodenum section (H\&E) in control and acrylamide groups. Sections from group I, the controls, show normal duodenum architecture with normal slender villi (black arrows) and crypts (red arrows) and no visible lesion(Ia and $\mathrm{Ib})$. Duodenal sections in the acrylamide $(7.5 \mathrm{mg} / \mathrm{kg}$ ) treated group exhibited severe coagulative necrosis and sloughing off of the villi (black arrow), necrotic debris of the intestinal lumen (blue arrow) and severe disruption and necrosis of the crypts of Lieberkühn (red arrow) (IIa). Duodenal sections from the acrylamide $(15 \mathrm{mg} / \mathrm{kg}$ ) treatment group showed stunted villi, with mild necrosis of the tips (black arrow). The crypts are also mildly affected (red arrow). At x400 sections in both experimental groups shows moderate polymorphonuclear cellular infiltration ( $\star$ ) and vascular congestion (\#) (IIb and IIIb) 

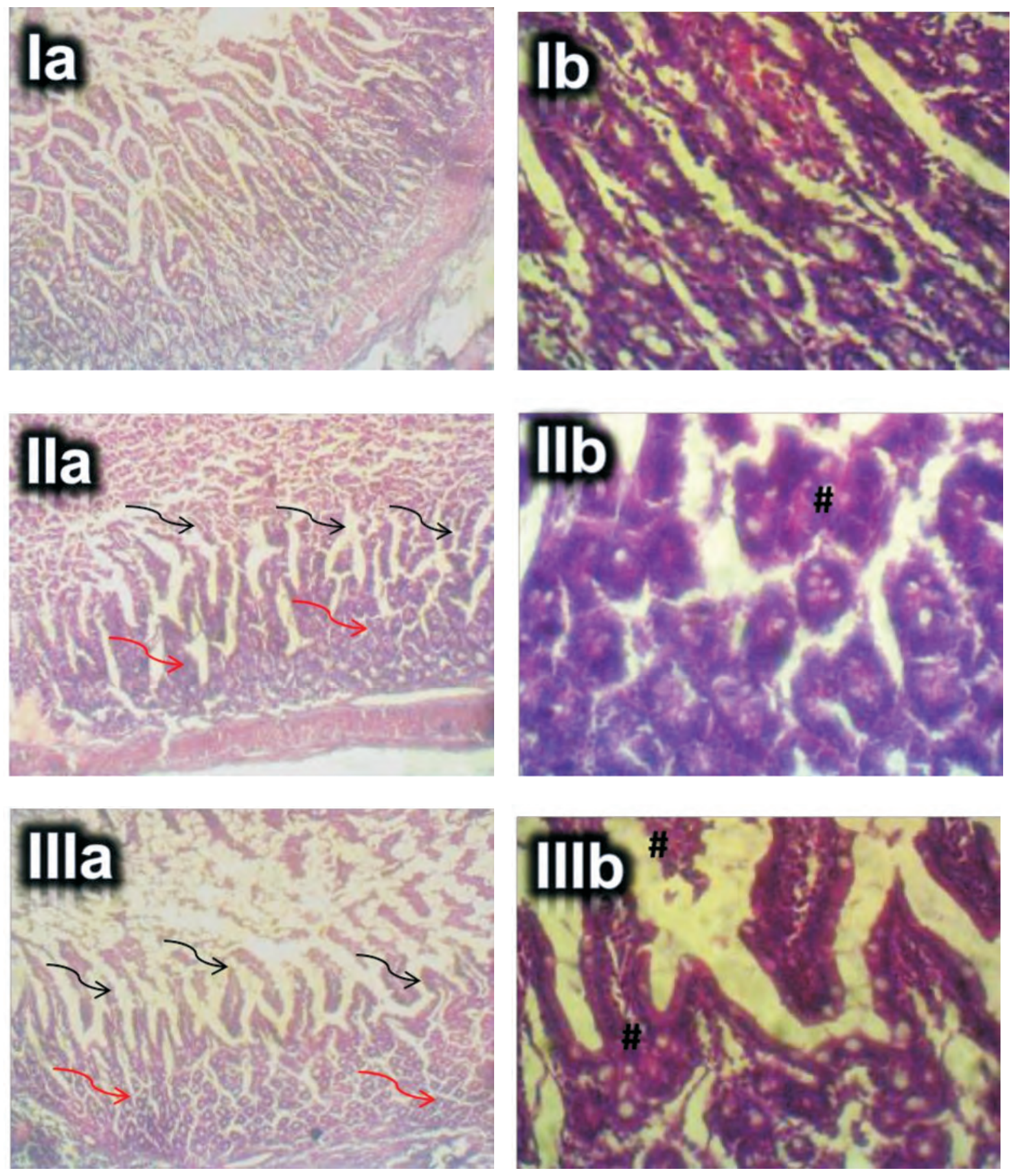

Figure 4 ( Ia-IIIa x100; Ib -IIIb x400) Jejunum section (H\&E) in control and acrylamide groups. The control group (group I) showed normal architecture consisting of sharp villi, goblet cells and normal crypts (Ia and Ib). Jejunal sections from the acrylamide $(7.5 \mathrm{mg} / \mathrm{kg})$ treatment group showed severe stunting and coagulative necrosis and sloughing off of the apical half of the villi. Cryptal cells were also moderately affected (red arrow). Jejunal samples in the acrylamide $(15 \mathrm{mg} / \mathrm{kg})$ treatment group showed severely stunted villi and coagulative necrosis of the apical half of the villi (black arrow). Crypts however appear normal (red arrows). At x400 sections from both experimental groups showed moderate vascular congestion (\#) (IIb and IIIb). 

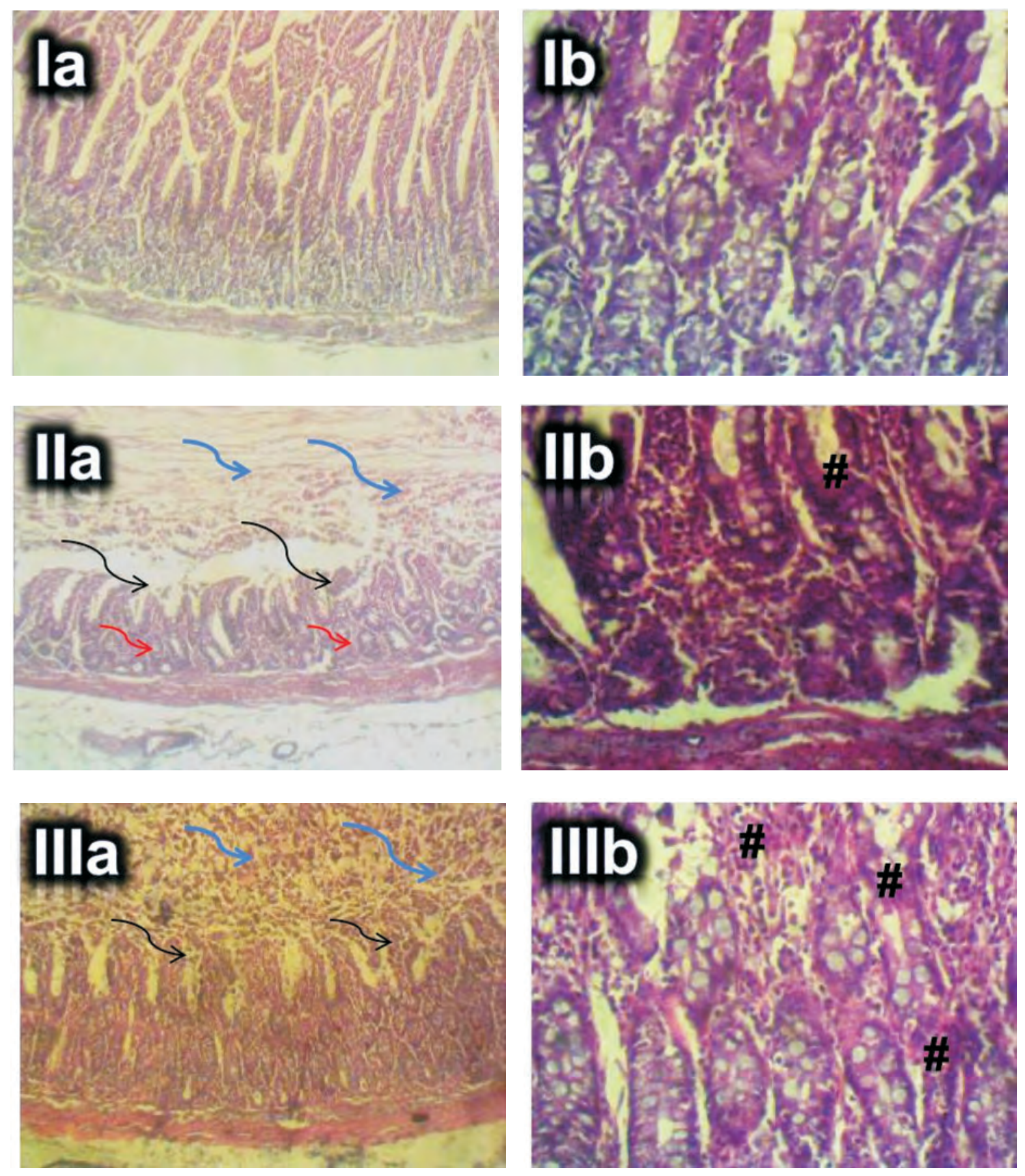

Figure 5 ( Ia-IIIa x100; Ib -IIIb x400). Ileum section (H\&E) in control and acrylamide groups. Group I, the control, shows normal architecture with normal slender villi (Ia) and crypts (Ib). In the acrylamide $(7.5 \mathrm{mg} / \mathrm{kg})$ treatment group, ileum sections showed severe stunting (atrophy) and coagulative necrosis with sloughing off of the apical half of the villi (black arrow) and a lot of epithelial debris in the lumen (blue arrows) (IIa). The crypts are unaffected although with mild vascular congestion (IIb). Ileum sections in the acrylamide $(15 \mathrm{mg} / \mathrm{kg})$ treatment group showed severe coagulative necrosis, stunting and sloughing off of the tips of the villi (black arrows) with a lot of debris in the lumen of the intestine (blue arrows). Crypts are unaffected appear unaffected however the some vascular congestion (\#) is observed (IIIb). 